\title{
Simulating bifacial perovskite/silicon tandem solar cells in large PV fields
}

\author{
Klaus Jäger, ${ }^{1,2, *}$ Peter Tillmann, ${ }^{1,2}$ Eugene A. Katz, ${ }^{3}$ and Christiane Becker ${ }^{1}$ \\ ${ }^{1}$ Helmholtz-Zentrum Berlin für Materialien und Energie, Hahn-Meitner Platz 1, 14019 Berlin, Germany \\ ${ }^{2}$ Zuse Institute Berlin, Takustraße 7, 14195 Berlin, Germany \\ ${ }^{3}$ Dept. of Solar Energy and Environmental Physics, The Jacob Blaustein Institutes for Desert Research, \\ Ben-Gurion University of the Negev, Sede Boqer Campus 8499000, Israel \\ *klaus.jaeger@helmholtz-berlin.de
}

\begin{abstract}
We report on simulations of idealized bifacial perovskite/silicon tandem solar cells which are placed in a large PV field. These simulations are used to perform energyyield optimizations for two- and four-terminal tandem cell configurations. (C) 2020 The Author(s)

OCIS codes: (350.6050) Solar energy; (040.5350) Photovoltaic; (000.4430) Numerical approximation and analysis;
\end{abstract}

\section{Introduction}

Silicon solar cells are by far the most important solar-cell technology - their efficiency is theoretically limited to $29.4 \%$ [1]. Two routes are intensively investigated to overcome this limit: (1) bifacial solar cells, where also light that falls on the back of the solar cell can be utilized and (2) tandem solar cells, where a cell with a higher bandgap is placed on top of a silicon solar cell in order to reduce thermalization losses. Tandem solar cells are developed in two main configurations: four-terminal cells, where the two subcells are not electrically collected, and monolithic two-terminal tandem solar cells, where the two subcells are electrically connected in series. While in four-terminal cells the two subcells can be operated completely independently of each other, in two-terminal cells the subcell, where the lower photon current density is generated, determines also the current density of the other subcell.

Already several studies estimated the energy yield of perovskite-silicon tandem solar cells [2-5]. These models consider isolated PV modules that are not affected by shading from modules in front of behind and only one work considers bifacial PV modules [5].

Recently, several of us developed a detailed model to calculate the illumination on the front and back sides of PV modules in a large PV field [6] and used it to maximize the energy yield for large silicon PV plants using Bayesian optimization [7]. In this contribution we apply the illumination model to bifacial perovskite-tandem solar cells. We will analyse the energy yield for two- and four-terminal tandem solar cells, which will allow us to compare these two concepts under realistic conditions.

\section{Model and Discussion}

Our illumination model calculates the illumination onto a PV module, which is considered to be in a PV field so large that effects from the first and last module rows and from the sides of the PV field can be neglected [6]. It considers four components, where each one is calculated for the module front and back: direct illumination from the Sun onto the module front, diffuse light from the Sky, diffuse light from the ground originating from direct sunlight and diffuse light from the ground originating from diffuse skylight.

For estimating the energy yield of ideal perovskite-silicon tandem solar cells, we assume a Shockley-Queisser model for the perovskite cell [8]. For the silicon cell, we use the approach by Richter et al., which also takes Auger recombination into account [1]. Further, we also consider luminescent coupling: if a subcell operates off the maximum power point in two-terminal operation, the fraction of the absorbed light, which is not converted into electrical energy, can be partially re-emitted as light, which can be utilized by the other subcell [9]. As the bandgap of the top cell is larger than the bottom-cell bandgap $(\approx 1.1 \mathrm{eV})$, only luminescence from the top cell, which increases the current density in the bottom cell, needs to be considered.

Figure 1 shows an example of the energy yield for two- and four-terminal cells with front and bifacial illumination. Four-terminal cells perform better than tandem cells and show almost no bandgap-dependence, which is in agreement with other studies [2,3]. Bifacial modules have a higher energy yield than monofacial modules. For the optimal bandgap, two-terminal cells perform only slightly worse than four-terminal cells. While for monofacial modules the optimal top-cell bandgap is around $1.73 \mathrm{eV}$, it shifts to around $1.65 \mathrm{eV}$ for bifacial modules in order to compensate for the higher bottom-cell current density from the light impinging at the back. For the lower bandgap range, the reported perovskite-cells perform better than for the higher bandgap range [10]. 


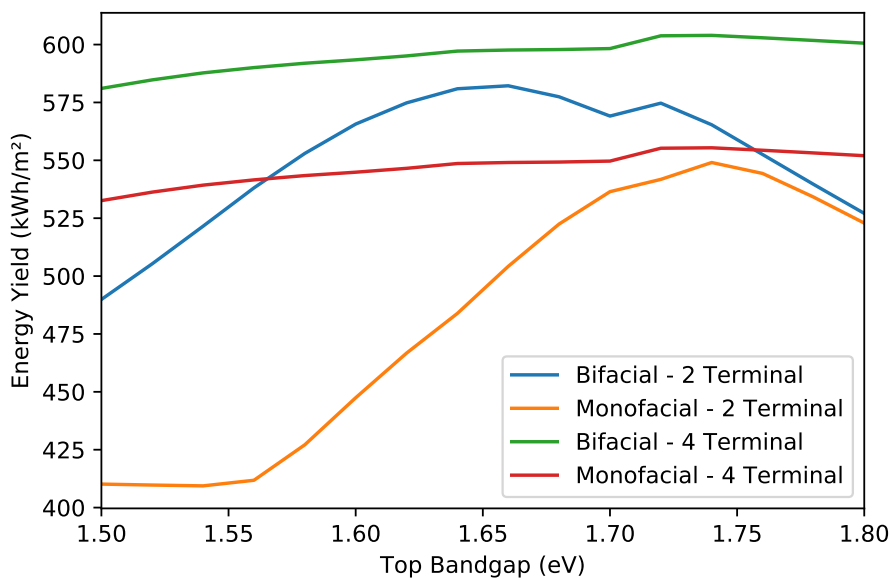

Fig. 1. The energy yield of a perovskite-tandem solar module (module height $1.96 \mathrm{~m}$ ) in Seattle for four different configurations as a function of the top-cell bandgap. The distance between two rows of modules is $8 \mathrm{~m}$, the bottom of the modules is $0.5 \mathrm{~m}$ above the ground. The module tilt angle was optimized for every bandgap. The annual energy density impinging onto the ground is $1137 \mathrm{kWh} / \mathrm{m}^{2}$.

\section{Conclusion}

Bifacial solar cells and tandem solar cells are two concepts, which potentially allow to increase the energy yield to values above silicon solar cell limits. For estimating the energy yield of bifacial tandem solar cell modules, accurate simulations are necessary, such as a recently developed illumination model for solar modules in a large PV field [6]. Calculations show that the optimal perovskite bandgap for monolithic bifacial tandem solar cells is around $1.65 \mathrm{eV}$ in contrast to $1.73 \mathrm{eV}$ for monofacial tandem solar cells. Perovskites with the lower bandgap are amongst the best-performing perovskite materials currently available.

\section{References}

1. A. Richter, M. Hermle, and S. Glunz, "Reassessment of the limiting efficiency for crystalline silicon solar cells," IEEE J. Photovolt. 3, 1184-1191 (2013).

2. M. T. Hörantner and H. J. Snaith, "Predicting and optimising the energy yield of perovskite-on-silicon tandem solar cells under real world conditions," Energy Environ. Sci. 10, 1983-1993 (2017).

3. M. H. Futscher and B. Ehrler, "Modeling the performance limitations and prospects of perovskite/si tandem solar cells under realistic operating conditions," ACS Energy Lett. 2, 2089-2095 (2017).

4. M. Jošt, E. Köhnen, A. B. Morales-Vilches, B. Lipovšek, K. Jäger, B. Macco, A. Al-Ashouri, J. Krč, L. Korte, B. Rech, R. Schlatmann, M. Topič, B. Stannowski, and S. Albrecht, "Textured interfaces in monolithic perovskite/silicon tandem solar cells: advanced light management for improved efficiency and energy yield,” Energy Environ. Sci. 11, 3511-3523 (2018).

5. R. Schmager, M. Langenhorst, J. Lehr, U. Lemmer, B. S. Richards, and U. W. Paetzold, "Methodology of energy yield modelling of perovskite-based multi-junction photovoltaics," Opt. Express 27, A507 (2019).

6. K. Jäger, P. Tillmann, and C. Becker, "Detailed illumination model for bifacial solar cells," Opt. Express 28, 4751 (2020).

7. P. Tillmann, K. Jäger, and C. Becker, "Minimising levelised cost of electricity of bifacial solar panel arrays using bayesian optimisation," Sustain. Energy \& Fuels 4, 254-264 (2020).

8. W. Shockley and H. J. Queisser, "Detailed balance limit of efficiency of p-n junction solar cells," J. Appl. Phys. 32, 510-519 (1961).

9. J. Jia, Y. Miao, Y. Kang, Y. Huo, M. Mazouchi, Y. Chen, L. Zhao, H. Deng, P. Supaniratisai, S. H. AlQahtani, and J. S. Harris, "Bias-dependence of luminescent coupling efficiency in multijunction solar cells," Opt. Express 23, A219 (2015).

10. M. Jošt, L. Kegelmann, L. Korte, and S. Albrecht, "Monolithic perovskite tandem solar cells: a review of the present status and advanced characterization methods towards 30\% efficiency," Adv. Energy Mater. p. accepted (2020). 